\title{
17-(Allylamino)-17-Demethoxygeldanamycin Combination with Curcumin Selectively Targets Mitogen Kinase Pathway in A Human Neuroblastoma Cell Line
}

\author{
Aftab Taiyab, Usha Kuppa Srinivas, Amere Subbarao Sreedhar \\ Centre for Cellular and Molecular Biology, Hyderabad, India. \\ Email: assr@ccmb.res.in
}

Received June $8^{\text {th }}$, 2010; revised June 30 ${ }^{\text {th }}, 2010$; accepted July $10^{\text {th }}, 2010$.

\begin{abstract}
Pharmacological inhibition of Hsp90 has emerged as a novel anticancer treatment. In this study we have investigated the effect of Hsp90 inhibitor drug 17AAG combination with curcumin on human neuroblastoma cells. The 17AAG treatment of cells for $18 \mathrm{~h}$ induced G1/S cell cycle arrest associated with cyclin D1 down regulation, and degradation of Raf-1 and inactivation of Akt. However, 17AAG treatment activated the mitogen kinase, ERK1, and induced the expression of stress proteins, Hsp70 and p53. The curcumin treatment resulted in G2/M cell cycle arrest and activation of both Raf1 and ERK1 kinases. The drugs in combination induced proteolytic degradation of Raf1 and Akt, and surpassed curcumin induced G2/M arrest. The combination treatment additionally inactivated MEK, inhibited activation and nuclear localization of ERK1, and also inhibited the stress protein induction. EGF stimulation induced re-activation of mitogen signaling with individual drug treatments but not in combination. This study highlights that 17AAG combination with curcumin selectively targets mitogen signal transduction mechanism through ERK1 inactivation. In conclusion, our study proposes the beneficial effects of $17 A A G$ combination with curcumin in combating cancer.
\end{abstract}

Keywords: Hsp90, 17AAG, Curcumin, Neuroblastoma, Combinatorial treatment

\section{Introduction}

Heat shock protein 90 (Hsp90) has shown to be involved in the conformational maturation and functional stabilization of several oncogenic proteins. Thus, inhibition of Hsp90 chaperone function using 17AAG (17-allylamino17-demethoxygeldanamycin) induces antitumor effects in tumor models [1,2]. Hsp90 inhibitors either induce cytostasis and/or apoptosis, therefore treatment of cancers with Hsp90 inhibitor drugs is thought to be irreversible $[3,4]$. Curcumin has been shown to elicit cytotoxicity in tumor cells through the activation of apoptosis $[5,6]$. Curcumin induced antitumor effects were primarily attributed to its inhibitory role against certain transcription factors [7], and are independent of heat shock protein inhibition [8].

Cell signaling pathways have been identified as potential pharmacological targets in antitumor treatments, therefore protein kinases are considered to be potential biomarkers [9,10]. Hsp90 stabilizes tyrosine kinases such as src, Lck, Abl, erb etc., and tyrosine kinase based growth factor receptors such as IGF (insulin growth factor), EGF (epidermal growth factor) and PDGF (platelet derived growth factor). In addition to tyrosine kinases, Hsp90 also interacts with serine-threonine kinases [11]. The Mitogen activated protein kinase (MAPK) pathways play important role in cell proliferation and survival and within the group of MAPKs, oncogenic transformation has been analyzed primarily in the context of signaling through Ras-Raf-MEK (MAP kinase kinase) leading to the activation of ERK (extracellular signal-regulated kinase) [12]. Cancer is a polygenic disease therefore targeting single kinase or pathway possibly will not account for effective combating of cancer since these cells have potential to activate alternate signaling [13].

In the recent years the combinatorial drug chemistry has emerged as a powerful tool for anticancer treatments. 17AAG combination with cytoskeletal protein inhibitors 
such as taxol was reported to be effective against cancer [14]. Similarly curcumin combination with EGCG (epigallocatechin gallate), cisplatin and doxorubicin were shown to target pro-survival pathways via NF-kB (nuclear factor-kappa B) [15]. There were reports that curcumin combination with piplartine augments the cytotoxic effects via ERK and cdk2 (cyclin dependent kinase-2) inactivation [8], and its combination with vitamin D3 induces differentiation [16]. Considering the present clinical interest with Hsp90 inhibitors and curcumin in anticancer treatments, we have examined and evaluated the effect of 17AAG in combination with curcumin in human neuroblastoma tumor cells, and report that the combination treatment effectively targets mitogen signaling through ERK1.

\section{Materials and Methods}

\subsection{Cell Culture and Chemicals}

The human neuoroblatoma tumor cells (IMR32) were maintained in Dulbecco's Modified Eagles Medium (DMEM) containing $10 \%$ fetal calf serum (FCS), penicillin $(100 \mathrm{U} / \mathrm{ml})$, and streptomycin $(50 \mu \mathrm{g} / \mathrm{ml})$ in a humidified incubator chamber $\left(37^{\circ} \mathrm{C}\right)$ supplied with $5 \% \mathrm{CO}_{2}$. All the chemicals are procured from Sigma Chemical Company, USA unless otherwise indicated.

\subsection{Drug Treatments}

Exponentially growing tumor cells $\left(1 \times 10^{6} / \mathrm{ml}\right)$ in complete medium were treated with different concentrations of 17AAG (Invitrogen; 0.5 to $10 \mu \mathrm{M}$ ), and curcumin (Sigma Aldrich; 1 to $25 \mu \mathrm{M}$ ) either alone or in combination. The EGF at a concentration $50 \mathrm{ng} / \mathrm{ml}$ (Sigma Aldrich) was used to confront drug treatments. All the treatments were continued with respective time intervals at $37^{\circ} \mathrm{C}$ before harvesting for further experiments.

\subsection{The Morphology, Viability, and FACS Analysis}

Cells after respective drug treatments were subjected to morphological examination using a regular phase contrast microscope (Nikon, TMS) attached to a $35 \mathrm{~mm}$ camera. Cell viability was determined by trypan blue exclusion assay before processing cells for further experiments. Control and drugs treated cells were washed with PBS (phosphate buffered saline), stained with 50 $\mu \mathrm{g} / \mathrm{ml}$ propidium iodide (containing $0.1 \%$ triton $\mathrm{X}-100$ and $22 \mu \mathrm{g} / \mathrm{ml}$ RNase), and analyzed in a fluorescence activated cell sorter (FACS Calibur, BD).

\subsection{MTT (3-(4,5-Dimethylthiazol-2-yl) -2, 5-diphenyltetrazolium bromide) Assay}

Neuroblastoma cells $\left(3 \times 10^{5}\right.$ cells/ml) were grown on 96 well plates, and the final volume of the medium in each well was maintained to $100 \mu \mathrm{l}$. Cells were treated with 17AAG, curcumin and their combination for $24 \mathrm{~h}$ followed by treatment with $10 \mu \mathrm{l}$ MTT (100 mg MTT/ 20 $\mathrm{ml}$ DMEM), for $6 \mathrm{~h}$ at room temperature with gentle shaking. The absorbance recorded at $590 \mathrm{~nm}$ using ELISA reader, and the formazan values obtained were interpreted such that an increase in absorbance is characteristic to increased cell death.

\subsection{Immunofluorescence and Laser Scanning Confocal Microscopy}

Neuroblastoma cells grown on cover slips (Fisher Scientifics, 22x22 mm) after respective drug treatments were rinsed with PBS, fixed in 3.7\% paraformaldehyde for 10 min, and permeabilized with $0.2 \%$ Triton X-100 for 10 min. Cells were then washed with PBS, blocked with PBS-Tween 20 (0.5\%; PBS-T) containing 2\% BSA for $30 \mathrm{~min}$, and incubated with primary antibody. After being washed with PBS-T, cells were incubated with corresponding FITC-conjugated secondary antibody (Bangalore Genie). Cover slips were mounted on slides with Slow-Fade mounting medium (Molecular Probes) and analyzed using a laser scanning confocal microscope (Olympus FV500 microscope).

\subsection{SDS-Polyacrylamide Gel Electrophoresis (SDS-PAGE) and Western Blot Analysis}

Cells after respective drug treatments were lysed using the lysis buffer (20 mM HEPES lysis buffer, $\mathrm{pH}$ 7.6 , 10 $\mathrm{mM} \mathrm{NaCl}, 1.5 \mathrm{mM} \mathrm{MgCl} 2,0.1 \%$ Triton X-100, $1 \mathrm{mM}$ dithiothretol) for $60 \mathrm{~min}$ at $4^{\circ} \mathrm{C}$. Protein concentration was estimated by Bradford method [17] using bovine serum albumin (BSA) as standard. Twenty micrograms of total cell lysate was mixed with Laemmli buffer [18] containing $100 \mu \mathrm{l}$ dithiothreitol, boiled for five minutes, and run on $10 \%$ SDS-PAGE. Proteins were transferred from the gel to nitro-cellulose membrane using a semidry protein gel transfer apparatus (Amersham Biosciences). Transfer of proteins was confirmed by Ponceau-S staining before processing gels for Western blot analysis. Membrane blocked with 3\% BSA followed by incubation with appropriate primary antibody for $1 \mathrm{~h}$ and subsequent incubation with horseradish peroxidase-conjugated secondary antibody (dilution, 1:3000) for $1 \mathrm{~h}$. The antigen- antibody interaction was visualized using luminol from BM-Chemiluminescence kit (Roche-Switzerland), and the protein bands exposed to X--ray film (Kodak). Antibodies used in the present study, ERK1 (1:1000), MEK1/2 (1:1000), Raf1 (1:1000), Akt (1:800), cyclin D1 (1:800) from Santa Cruz (USA). The antibodies actin (1:500), $\beta$-tubulin (1:500), Hsp70 (1:1000), Hsp27 
(1:1000), p53 (1:500), and p21 (1:750) are from Stressgen, (USA). The dilutions were mentioned after each respective antibody in closed brackets.

\subsection{Statistical Analysis of Data}

Data reported as mean \pm SD value from the average of three independent experiments. The control groups were compared with drug treated ones, and the significance values were calculated by paired student's $t$-test. The $P$ values represented are $* * * \mathrm{P}<0.001$, ** $\mathrm{P}<0.01$, and * $\mathrm{P}<0.05$ ”.

\section{Results}

\subsubsection{AAG and Curcumin both Induces Dose-Dependent Cytotoxicity in Human Neuroblastoma}

Different concentrations of 17AAG were examined against neuroblastoma cells for $18 \mathrm{~h}$, and the cytotoxicity was measured by MTT assay. We observed a concentration dependent cytotoxicity reaching $62 \%$ at $10 \mu \mathrm{M}$ concentrations (Figure 1(a)). Similarly, curcumin treatment for $24 \mathrm{~h}$ showed cytotoxicity only at above $20 \mu \mathrm{M}$ concentration. Notably $10 \mu \mathrm{M}$ 17AAG showed $>50 \%$ cell death, and maximum cytotoxicity (100\%) observed with curcumin was at $25 \mu \mathrm{M}$ concentration (Figure 1(b)). Considering minimal cell death induced by these drugs than reported at low concentrations, we have used combination treatment of 17AAG $(2 \mu \mathrm{M})$ with curcumin $(15$ $\mu \mathrm{M})$. The combination treatment however not resulted in any significant cell death in $24 \mathrm{~h}$ treatment (Figure 1(c)). Therefore we analyzed for potential effect of individual drugs on cell cycle, and observed 17AAG induced G1/S and curcumin induced G2/M arrest. Interestingly, in the

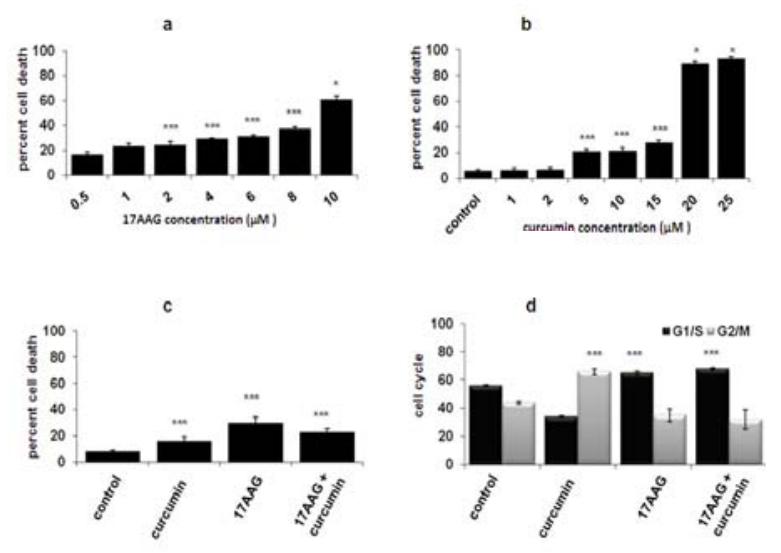

Figure 1. 17AAG, curcumin, and their combination on drug induced cytotoxicity. (Figure 1(a), 1(b), and 1(c)). Control values are normalized with treatment in Figure 1(a). Cell cycle analysis of drug treated neuroblastoma shows differential cell cycle arrest (Figure 1(d)). combination treatment, 17AAG surpassed curcumin induced G2/M arrest and thus arrested cells in G1/S phase of cell cycle (Figure 1(d)).

\subsection{AAG and Curcumin Combination Selectively Targets Mitogen Signaling Pathway}

Anti-Hsp90 drugs dissociate Hsp90 from Hsp90-client protein interaction that induces destabilization of client proteins [11]. However, curcumin induced proteolytic degradation of oncogenic kinases was not reported [19]. Therefore, the effect of individual drugs and their combination was tested against activation and degradation of various serine-threonine kinases such as Raf1, Akt, MEK and ERK kinases. We observed that while curcumin treatment was inducing Raf1 activation, 17AAG treatment resulted in its proteolytic degradation. The basal expression of Akt was though not affected by these drugs, 17AAG alone and in combination with curcumin inhibited Akt activation. While individual drug treatments increased ERK1 phosphorylation, the combination treatment resulted in significant inhibition of its activation, and additionally induced its degradation. The combination treatment further resulted in induced degradation of MEK (Figure 2).

\subsection{AAG Treatment Surpasses Curcumin Induced Cycle Arrest}

Cell cycle machinery controls cell proliferation, and cancer is a disease of inappropriate cell proliferation. In
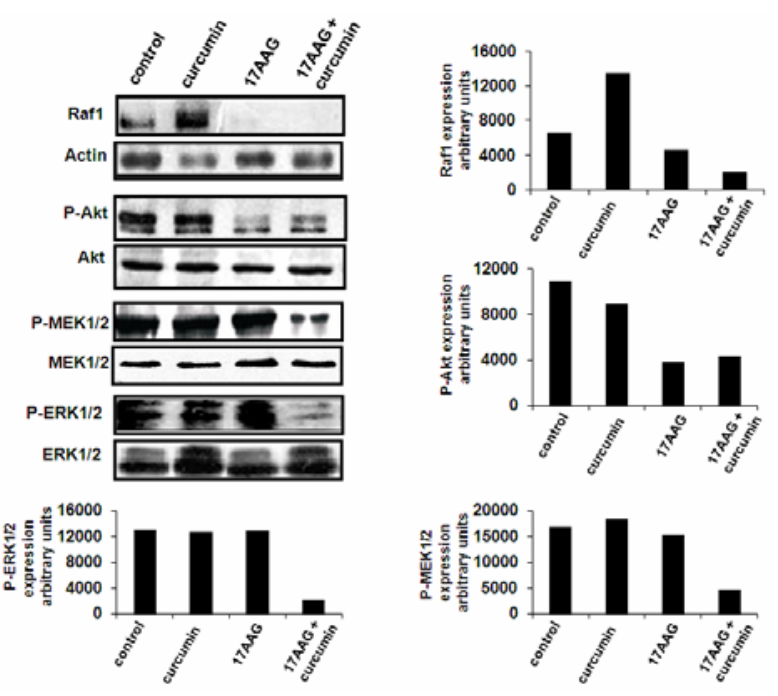

Figure 2. Drugs induced differential signaling response. Note only 17AAG and its combination with curcumin induced inactivation of Akt followed by inactivation of MEK and ERK. The densitometric plots shows fold decrease. Actin was used as loading control. 
addition to kinase specific inhibitors that also inhibit cell division, irreversible cell cycle inhibition alone is thought to be effective in successful combating of cancer [20]. The cell cycle inhibition usually correlates with increased p21 and decreased cyclin D1 expressions, therefore we analyzed for the expression of these molecules by immunoblot analysis. We observed a correlation of our cell cycle study with induced expression p21 and decreased levels of cyclin D1 (Figure 3).

\subsection{Curcumin Combination Inhibits the Stress Response Induced by 17AAG}

Usually cell cycle arrest proceeds to either apoptosis or differentiation [21]. From the analysis of neuronal differentiation markers such as Map2, Gad67, heavy neurofilament we found that these drugs do not induce differentiation (data not presented), nevertheless, accumulation of cells in G1/S phase of cell cycle suggested activation of stress response. In contrast to curcumin, 17AAG treatment induced Hsp70 and p53 protein expression, whereas curcumin and 17AAG treatments have independently induced Hsp27 expression, however, the combination treatment has resulted in the inhibition of Hsp70, p53 and Hsp27 induction. A diminutive decrease in Hsp90 expression was observed upon 17AAG and its combination with curcumin treatments (Figure 4).

\subsection{Effect of 17AAG and Curcumin on ERK1 Signaling}

MAPK pathway plays an important role in signal transduction in response to a wide variety of extracellular signals [22]. Since combination drug treatment resulted in the inactivation of ERK1 despite of its stable activa
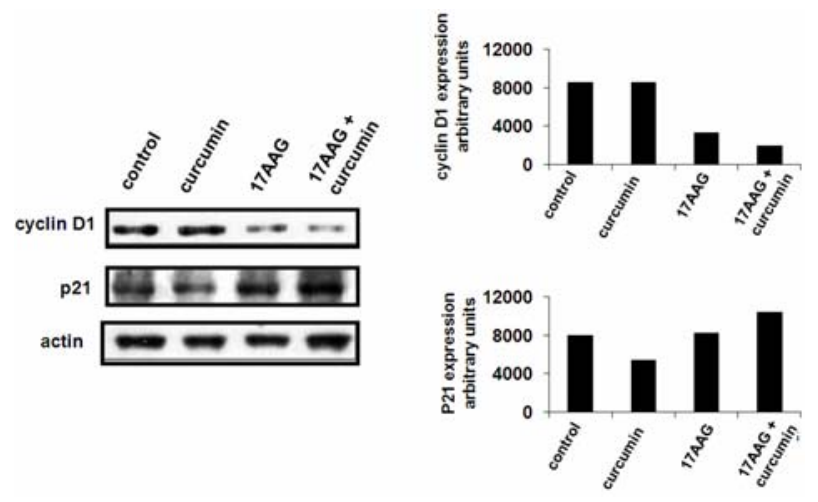

Figure 3. Drugs induced effects on cell cycle proteins. Note a significant decrease in cyclin D1 levels, and a gradual increase in p21 levels after 17AAG treatment and its enhancement in combination treatment with curcumin. The densitometric plots shows fold decrease in the expression of signaling molecule. Actin immunoblot used as loading control.
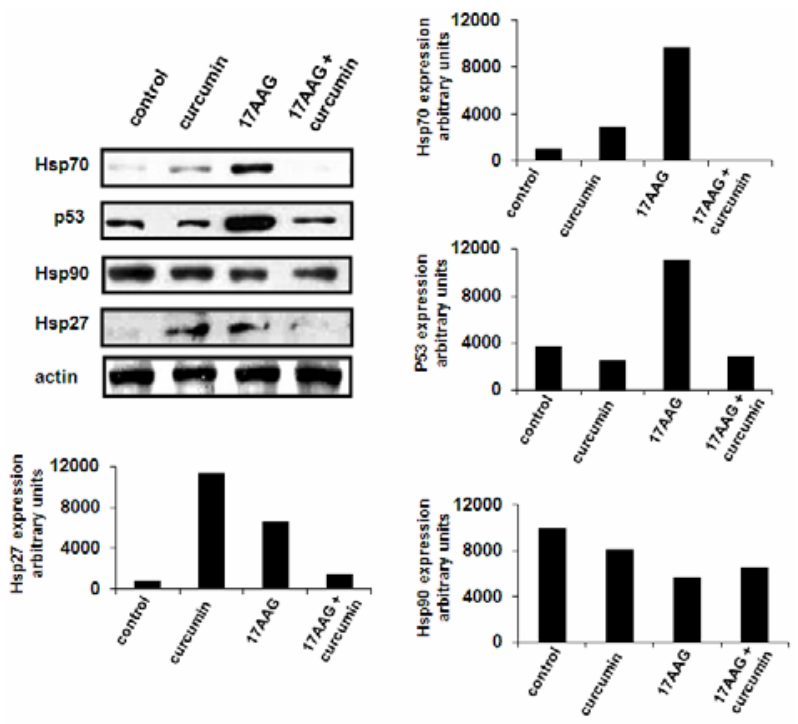

Figure 4. Drugs effect on stress proteins. Note 17AAG treatment induced expression of Hsp70, p53 and both curcumin and 17AAG induced Hsp27 levels. Also note that inhibition of stress response in the combination treatment. The densitometric plots shows fold decrease in the expression of signaling molecule. Actin immunoblot used as loading control.

tion in individual drug treatments (Figure 2), we examined for ERK1 cellular localization by immunofluorescence analysis. From the immunoflourescence study in control cells, phosphorylated ERK1 localization was observed both in peri-nuclear and cytoplasmic accretion; however, curcumin and 17AAG treatments induced its nuclear translocation. In the combination treatment, we observed both inactivation as well as decreased nuclear

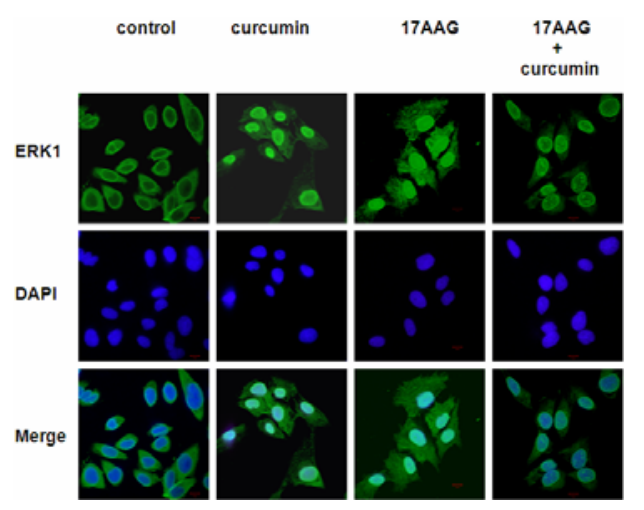

Figure 5. Drugs induced re-localozation of activated ERK1 by confocal scanning microscopy. Rows represents control, curcumin, 17AAG, and 17AAG in combination with curcumin, and the columns represents ERK1 (green), nucleus staining with DAPI (blue), and merge (green + blue). Note ERK1 nuclear localization in curcumin and 17AAG treatments compared to control, and inability in nuclear localization treament. 
localization of ERK1 (Figure 5).

\subsection{Effect of Epidermal Growth Factor in the Reversal of Mitogen Signal Inactivation}

The membrane receptors, including EGF, transduce signals by activating the MAPK family of proteins; therefore tumor cells take advantage of these kinases for constitutive activation of survival signals. In the present study, to examine whether our combination is selectively targeting the mitogen signaling pathway, we evaluated EGF effect in 17AAG and curcumin combination drug pre-treatment (EGF treatment followed by combination drugs), co-treatment (EGF treatment along with combination of drugs) and post-treatments (EGF treatment after the combination drug treatment). The EGF treatment induced reversal of cytotoxicity in the combination treatments significantly, however, was not found to be effective with 17AAG treatment alone. Among the pre-, co-, and post- EGF treatments, the co- and post-treatments showed decreased cell recovery compared to the pre-treatment (Figure 6). The improved growth in EGF pre-treatment could be related to enhanced proliferative signaling prior to drugs treatment, whereas co- and post-treatments suggests absence or lowered proliferation rate due to combination of drugs. These findings invoked existence of possible signal transduction dependent regulatory mechanism operated by EGF in the reversal of 17AAG effect however only in the combination treatment. In support, the immunoblot analysis of EGF treated cells showed restrained Raf1, Akt and MEK activities but resulted in enhanced proteolytic degradation of ERK1 (Figure 7).

\section{Discussion}

Among several anticancer drugs that are under clinical evaluation, Hsp90 inhibitor drug 17AAG [23-24] and antioxidant and anti-inflammatory drug curcumin [6] are attributed for their selectivity and specificity against a large variety of cancer cells. Considering the growing interest and beneficial effects of combinatorial drug treatments in treating cancer, we have examined for combinatorial effects of 17AAG and curcumin against human neuroblastoma tumor cells. From the present study, we report that the combination drug treatment selectively targets the MAP kinase signal transduction pathway.

Several reports of 17AAG combination with oxaliplatin, flurouracil [25], carboplatin [26], paclitaxel [27], rapamycin [28], trastuzumab and tanespinycin [29], histone deacetylease [30] etc., suggests that 17AAG combination treatments not only enhance drug specific effects, but exhibit synergistic effects however not though MAP kinases. In a classical mitogen activated

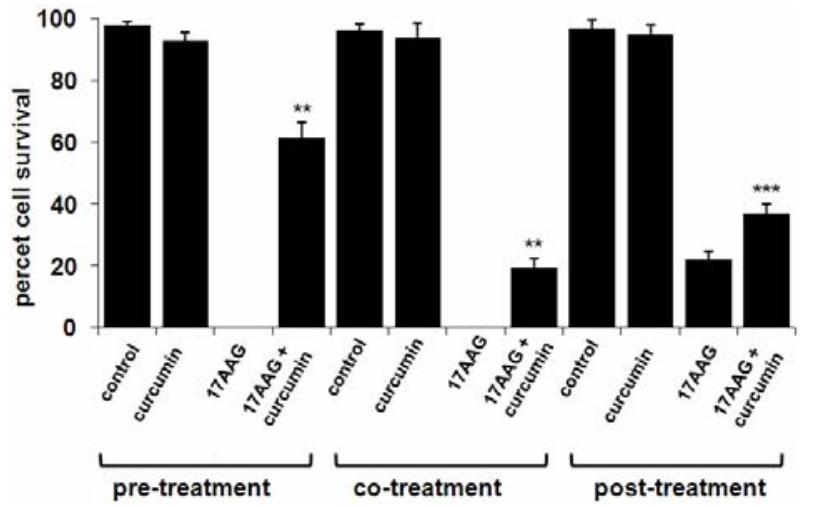

Figure 6. Epidermal growth factor (EGF) treatment on cell recovery and mitogen signal activation. Compared to 17AAG treatment its combination with curcumin shows reversal of phenotype. Note that only post-treatment of cells with EGF shows maximum survival compared to co- and pre-treatments.
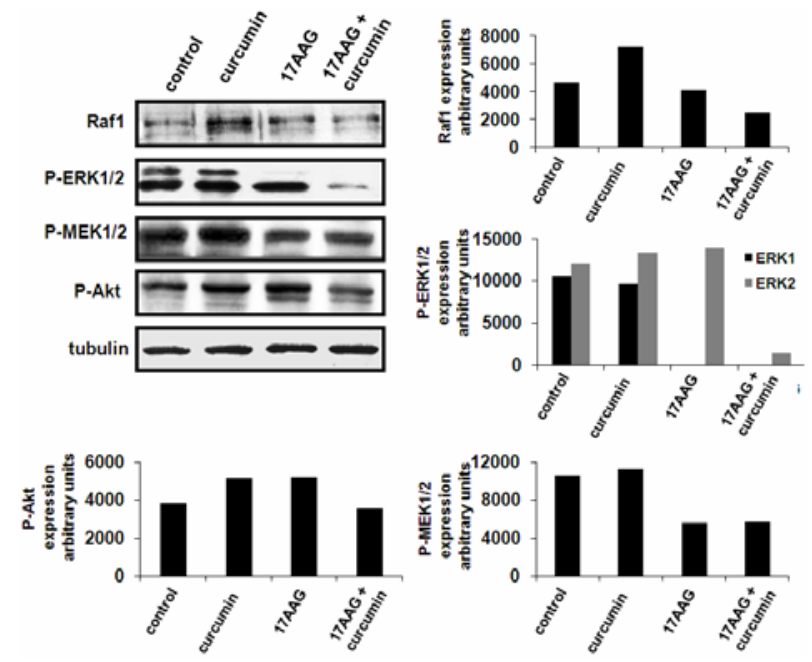

Figure 7. Drugs induced differential signaling response after EGF recovery. Note only 17AAG and its combination with curcumin induced inactivation of Akt, MEK and ERK. The densitometric plots shows fold decrease. Tubulin used as loading control.

signaling pathway MEK binds to ERK and this coordinated binding is essential for the activation of ERK. Deregulated signal transduction mechanism is one of the hall marks of cancers [31,32]. From our studies it is evident that Raf1 activation by curcumin or inactivation by 17AAG has no or little effect on MEK and ERK signaling, therefore, the Akt or Raf1 activation appears to be independent of downstream effectors of MAPK pathway. Usually only one form of dual phopshorylated ERK exists in the cell with greater specificity, which translocates to the nucleus and activates certain transcriptional factors. In agreement with curcumin induced ERK and JNK 
pathways [33], we report ERK1 activation and its nuclear localization with 17AAG and curcumin, however, the combination has significantly inhibited its activation and nuclear translocation.

Despite the fact that curcumin alone can activate stress response in experimental models $[34,35]$, in our system curcumin did not induce stress response. Curcumin on the other hand had inhibited stress response induced by 17AAG. Similar results were obtained with different cell types such as rat histiocytoma (BC-8), rat hepatoma cells (CRL-1600), human T-lymphocyte cells (Jurkat), mouse embryonal carcinoma cells (PCC4). Induced stress proteins are known to hamper cancer treatments, therefore, drugs that induce cytotoxic effects without inducing the stress response are considered to be effective anticancer agents [36]. Only a decrease in $\mathrm{BCl} 2$ expression in association with increased stress proteins further suggests activation of only the stress response, but not apoptotic response. Treatment of tumor cells with ROS (reactive oxygen species) scavenger, NAC (N-acetyl cysteine), ascorbic acid, vitamin $\mathrm{K}$ etc., though decreased ROS levels, they did not show any effect on combination treatment induced mitogen signal targeting (data not shown). Contrary to curcumin induced p21 and degradation of cyclin D1 [5,37], we did not find curcumin targeting of these two molecule. However, once again it is only the combination treatment that had resulted in the degradation of cyclin D1, which is otherwise found deregulated in majority of cancers [38].

The EGF and EGF-receptor signaling stimulates growth of cells in culture without affecting DNA synthesis [39]. Neuroblastoma tumors are known to have induced expression of EGF family of receptors [40]. Observing a MAPK dependent targeting in our combinatorial drug treatment with 17AAG and diferuloylmethane, we have examined for EGF effect on drug treated cells and found that EGF stimulation though resulted in the restitution of normal division potential, selective targeting of ERK signaling was established.

We present that 17AAG combination with curcumin potentiated 17AAG effect and additionally targeted MAP kinases. Combination treatment further inhibited 17AAG induced stress response. Our results indicate that 17AAG may be a promising candidate to use in combinatorial treatments with curcumin to combat cancer where mitogen kinase expression is challenging the anticancer treatment.

\section{Acknowledgements}

Authors thank Ms. Nandini for confocal microscopy. Department of Biotechnology and Department of Science and Technology, Ministry of Human Resource De- velopment, Government of India supported the work in author's laboratory.

\section{REFERENCES}

[1] L. Whitesell, E. G. Mimnaugh, B. De Costa, C. E. Myers and L. M. Neckers, "Inhibition of Heat Shock Protein Hsp90-pp60v-src Heteroprotein Complex Formation by Benzoquinone Ansamycins: Essential Role for Stress Proteins in Oncogene Transformation," Proceedings of National Academy of Sciences USA, Vol. 91, No. 18, 1994, pp. 8324-8328.

[2] A. Kamal, L. Thao, J. Sensintaffar, L. Zhang, M. F. Boehm, L. C. Fritz and F. J. Burrows, "High Affinity Conformation of Hsp90 Confers Tumor Selectivity on Hsp90 Inhibitors,” Nature, Vol. 425, No. 6956, 2003, pp. 207-410.

[3] T. Vanden Berghe, M. Kalai, G. van Loo, W. Declerq and P. Vandenbeele, "Disruption of HSP90 Function Reverts Tumor Necrosis Factor-induced Necrosis to Apoptosis," Journal of Biological Chemistry, Vol. 278, No. 9, 2003, pp. 5622-5629.

[4] I. Hostein, D. Robertson, F. DiStefanco, P. Workman, and P. A. Clarke, "Inhibition of Signal Transduction -by the Hsp90 Inhibitor 17-allylamino-17-demethoxygeldanamycin results in Cytostasis and Apoptosis," Cancer Research, Vol. 61, No. 10, May 2001, pp. 4003-4009.

[5] B. B. Aggarwal, A. Kumar and A. C. Bharti, "Anticancer Potential of Curcumin: Preclinical and Clinical Studies," Anticancer Research, Vol. 23, No. 1A, 2003, pp. 263-398.

[6] A. L. Cheng, C. H. Hsu, J. K. Lin, M. M. Hsu, Y. M. Ho, T. S. Shen, J. Y. Ko, Lin J. T, Lin B. R, Ming-Shiang W, Yu H. S, Jee S. H, Chen G. S, Chen T. M, Chen C. A, Lai M. K, Lai M. K, Pu Y. S, Pan M. H, Wang Y. J, Tsai C. C and Hsieh C. Y, "Phase I Clinical Trial of Curcumin, a Chemopreventive Agent, in Patients with High-risk or Pre-malignant Lesions,” Anticancer Research, Vol. 21, No. 4B,2001, pp. 2895-2900.

[7] A. Duvoix, R. Blasius, S. Delhalle, M. Schnekenburger, F. Morceau, E. Henry, M. Dicato and M. Diederich, "Chemopreventive and Therapeutic Effects of Curcumin," Cancer Letters, Vol. 223, No. 2, 2005, pp. 181-190.

[8] D. Jyothi, P. Vanathi, P. Mangala Gowri, V. Rama Subba Rao, J. Madhusudana Rao and A. S. Sreedhar, "Diferuloylmethane Augments the Cytotoxic Effects of Piplartine Isolated from Piper Chaba,” Toxicology In Vitro, Vol. 23, No. 6, 2009, pp. 1085-1091.

[9] A. H. Bild, G. Yao, J. T. Chang, Q. Wang, A. Potti, D. Chasse, M. B. Joshi, D. Harpole, J. M. Lancaster, A. Berchuck, J. A. Olson Jr, J. R. Marks, H. K. Dressman, M. West and J. R. Nevins, "Oncogenic Pathway Signatures in Human Cancers as a Guide to Targeted Therapies," Nature, Vol. 439, No. 7074, 2006, pp. 353-357.

[10] A. H. Bild, A. Potti and J. R. Nevins, "Linking Oncogenic Pathways with Therapeutic Opportunities," Nature Review Cancer, Vol. 6, No. 9, 2006, pp. 735-741. 
[11] W. B. Pratt and D. O. Toft, "Regulation of Signaling Protein Function and Trafficking by the Hsp90/hsp70based Chaperone Machinery,” Experimental Biology and Medicine, Vol. 228, No. 2, 2003, pp.111-133.

[12] P. Blume-Jensen and T. Hunter, "Oncogenic Kinase Signaling,” Nature, Vol. 411, No. 6835, 2001, pp. 355-365.

[13] A. S. Sreedhar, P. Vanathi and K. R. Paithankar, "Stress Protein in Biology and Medicine: Evolution, Adaptation and Clinical Evaluation," International Journal of Pharma and Biosciences, Vol. 1, No. 3, 2010, pp. 1-36.

[14] D. B. Solit, A. D. Basso, A. B. Olshen, H. I. Scher and N. Rosen, "Inhibition of Heat Shock Protein 90 Function Down-regulates Akt kinase and Sensitizes Tumors to Taxol," Cancer Research, Vol. 63, No. 9, 2003, pp. 2139-2144.

[15] A. K. Ghosh, N. E. Kay, C. R. Secreto and T. D. Shanafelt, "Curcumin Inhibits Prosurvival Pathways in Chronic Lymphocytic Leukemia B Cells and May Overcome Their Stromal Protection in Combination with EGCG,” Clinical Cancer Research, Vol. 15, No. 4, 2009, pp. 1250-1258.

[16] J. A. Sokoloski, K. Shyam and A. C. Sartorelli, "Induction of the Differentiation of HL-60 Promyelocytic Leukemia Cells by Curcumin in Combination with Low Levels of Vitamin D3,” Oncology Research, Vol. 9, No. 1, 1997, pp. 31-39.

[17] M. M. Bradford, "A Rapid and Sensitive Method for the Quantitation of Protein Utilizing the Principle of Protein-dye Binding,” Anal Biochemistry, Vol. 7, 1976, pp. 248-254.

[18] U. K. Laemmli, "Cleavage of Structural Proteins during the Assembly of the Head of Bacteriophage T4,” Nature, Vol. 227, No. 5259, 1970, pp. 680-685.

[19] L. Neckers, "Screening for Inducers of Kinase Degradation,” Chemistry \& Biology, Vol. 10, No. 7, 2003, pp. 587-589.

[20] M. B. Kastan and J. Bartek, "Cell-cycle Checkpoints and Cancer," Nature, Vol. 432, No. 7015, 2004, pp. 316-328.

[21] D. Alesiani, R. Cicconi, M. Mattei, C. Montesano, R. Bei and A. Canini, "Cell Cycle Arrest and Differentiation Induction by 5,7-dimethoxycoumarin in Melanoma Cells. International Journal of Oncology, Vol. 32, No. 2, 2008, pp. 425-434.

[22] M. D. Brown and D. B. Sacks, "Protein Scaffold in MAP Kinase Signaling,” Cell Signalling, Vol. 21, No.4, 2009, pp. 462-469.

[23] S. Pacey, U. Benerji, I. Judson and P. Workman, "Hsp90 Inhibitors in the Clinic," Handbook of Experimental Pharmacology, Vol. 172, 2006, pp. 331-358.

[24] A. S. Sreedhar, C. Soti and P. Csermely, "Inhibition of Hsp90: A New Strategy for Inhibiting Protein Kinases," Biochimica et Biophysica Acta, Vol. 1697, No. 3, 2004, pp. 233-242.

[25] T. V. Rakitina, I. A. Vasilevskaya and P. J. O'Dwyer,
"Inhibition of G1/S Transition Potentiates Oxaliplatininduced Cell Death in Colon Cancer Cell Lines,” Biochemical Pharmacology, Vol. 73, No. 11, 2007, pp. 1715-1726.

[26] U. Banerji, N. Sain, S. Y. Sharp, M. Valenti, Y. Asad, R. Ruddle, F. Raynaud F, M. Walton, S. A. Eccles, I. Judson, A. L. Jackman and P. Workman, "An in Vitro and in Vivo Study of the Combination of the Heat Shock Protein Inhibitor 17-allylamino-17-demethoxygeldanamycin and Carboplatin in Human Ovarian Cancer Models,” Cancer Chemotherapy and Pharmacology, Vol. 62, No. 5, 2008, pp. 769-778.

[27] N. Sain, B. Krishnan, M. G. Ormerod, A. De Rienzo, W. M. Liu, S. B. Kaye, P. Workman and A. L. Jackman, "Potentiation of Paclitaxel Activity by the HSP90 Inhibitor 17-allylamino-17-demethoxygeldanamycin in Human Ovarian Carcinoma Cell Lines with High Levels of Activated AKT," Molecular Cancer Therapy, Vol. 5, No. 5, 2006, pp. 1197-1208.

[28] M. M. Roforth and C. Tan, "Combination of Rapamycin and 17-allylamino-17-demethoxygeldanamycin Abrogates Akt Activation and Potentiates mTOR Blockade in Breast Cancer Cells,” Anticancer Drugs, Vol. 19, No. 7, 2008, pp. 681-688.

[29] S. Modi, A. T. Stopeck, M. S. Gordon, D. Mendelson, D. B. Solit, R. Bagatell, W. Ma, J. Wheler, N. Rosen, L. Norton, G. F. Cropp, R. G. Johnson, A. L. Hannah and C. A. Hudis, "Combination of Trastuzumab and Tanespimycin (17-AAG, KOS-953) is Safe and Active in Trastuzumab-refractory HER-2 Overexpressing Breast Cancer: A Phase I Dose-escalation Study," Journal of Clinical Oncology, Vol. 25, No. 34, 2007, pp. 5410-5417.

[30] G. Ravi, P. George, P. Bali, J. Tao, F. Guo, C. Sigua, Y. Li, L. Moscinski, P. Atadja and K. N. Bhalla, “A Combination of Histone Deacetylase Inhibitor LBH589 and the Hsp90 Inhibitor 17-AAG is Highly Active Against Human CML-BC and AML Cells with Constitutively Active Mutant FLT-3 Tyrosine Kinase,” Abstract 3023, Experimental and Molecular Therapeutics 28: Novel Targets and approaches for angiogenesis and Signaling pathways, 2004.

[31] D. Hanahan and R. A Weinberg, "The Hallmarks of Cancer,” Cell, Vol. 7, No. 1, 2000, pp. 57-70.

[32] D. T. Denhardt, "Oncogene-initiated Aberrant Signaling Engenders the Metastatic Phenotype: Synergistic Transcription Factor Interactions are Targets for cancer therapy," Critical Reviews in Oncogenesis, Vol. 7, No. 3-4, 1996, pp. 261-291.

[33] B. H. Choi, C. G. Kim, Y. S. Bae, Y. Lim, Y. H. Lee and S. Y. Shin, "P21 Waf1/Cip1 Expression by Curcumin in U-87MG Human Glioma Cells: Role of Early Growth Response-1 Expression," Cancer Research, Vol. 68, pp. 1369-1377, 2008.

[34] A. Khar, A. M. Ali, B. V. V. Pardhasaradhi, C. H. Varalakshmi, R. Anjum and A. L. Kumari, "Induction of Stress Response Renders Human Tumor Cell Lines Resistant to Curcumin-mediated Apoptosis: Role of Reac- 
tive Oxygen Intermediates," Cell Stress and Chaperones, Vol. 6, No. 4, 2001, pp. 368-376.

[35] K. Kato, H. Ito and K. Kamei, "Iwamoto I. Stimulation of the stress-induced expression of stress proteins by Curcumin in cultured cells and in rat tissues in vivo," Cell Stress and Chaperones, Vol. 3, No. 3, 1998, pp. 152-160.

[36] A. S. Sreedhar and P. Csermely, "Heat Shock Proteins in the Regulation of Apoptosis: New Strategies in Tumor Therapy. A Comprehensive Review,” Pharmacology and Therapeutics, Vol. 101, No. 3, 2004, pp. 227-257.

[37] A. B. Kunnumakkara, P. Diagaradjane, P. Anand, K. B. Harikumar, A. Deorukhkar, J. Gelovani, S. Guha, S. Krishnan and B. B. Aggarwal, "Curcumin Sensitizes Human Colorectal Cancer to Capecitabine by Modulation of Cyclin D1, COX-2, MMP-9, VEGF and CXCR4 Ex- pression in an Orthotopic Mouse Model," International Journal of Cancer, Vol. 125, No. 9, 2009, pp. 2187-2197.

[38] K. Pruitt and C. J. Der, "Ras and Rho Regulation of the Cell Cycle and Oncogenesis,” Cancer Letters, Vol. 171, No. 1, 2001, pp. 1-10.

[39] T. Putz, Z. Culig, I. E. Edler, C. Nessler-Menardi, G. Bartsch, H. Grunicke, F. Uberall and H. Klocker, "Epidermal Growth Factor (EGF) Receptor Blockade Inhibits the Action of EGF, Insulin-like Growth Factor I, and a Protein Kinase A Activator on the Mitogen-activated Protein kinase Pathway in Prostate Cancer Cell Lines,” Cancer Research, Vol. 59, No. 1, 1999, pp. 227-233.

[40] H. Sartelet, L. L. Oligny and G. Vassal, "AKT Pathway in Neuroblastoma and Its Therapeutic Implication,” EXpert Review of Anticancer Therapy, Vol. 8, No. 5, 2008, pp. 757-769. 